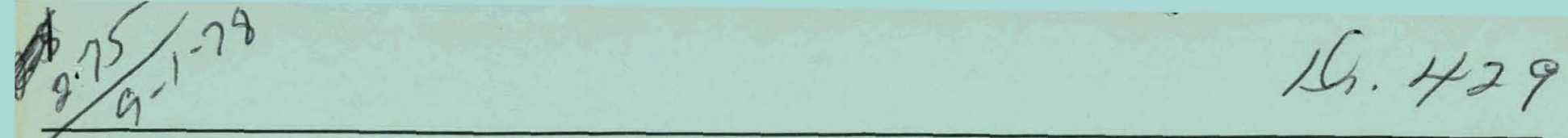

Prepared for U.S. Department of Energy

August 1978

Assistant Secretary for Energy Technology

Division of Fossil Fuel Utilization

\title{
Corn/Coal Fuel \\ Characterization Study
}
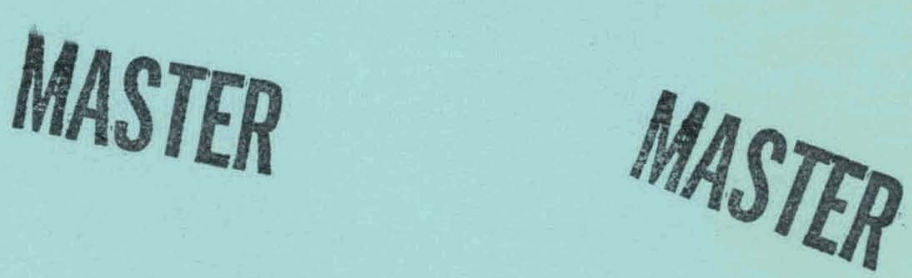


\begin{tabular}{|c|c|c|c|}
\hline \multirow[b]{2}{*}{ Sample No. } & \multirow[b]{2}{*}{ Sample - } & \multicolumn{2}{|c|}{ Grindability } \\
\hline & & CGI & $\begin{array}{c}\text { HGI } \\
\text { (ASTM D-409) }\end{array}$ \\
\hline$M-40300$ & Corm & $\begin{array}{l}\text { See } \\
\text { Comments } \\
\text { Below }\end{array}$ & 27 \\
\hline C-14461 & Coal & 65 & 67 \\
\hline F-1426 & $\begin{array}{l}90 \% \text { coal } / \\
10 \% \text { corn } \\
\text { BTU basis }\end{array}$ & 43 & 57 \\
\hline F-1427 & $\begin{array}{l}80 \% \text { coal } / \\
20 \% \text { corn } \\
\text { BTU basis }\end{array}$ & 34 & 49 \\
\hline F-1428 & $\begin{array}{l}70 \% \text { coal } / \\
30 \% \text { corn } \\
\text { BTU basis }\end{array}$ & 28 & 42 \\
\hline
\end{tabular}

A general description of the continuous laboratory scale mill appears in Attachment B. The continuous mill testing is performed using 2 to 5 pounds of air dried, $16 \times 30$ mesh samples. A preliminary empirical correlation of apparent full scale grindability (obtained from field measurements) with laboratory continuous mill performance has been derived from the testing of selected coal samples in the Continuous Grindability Mill. As a result of these tests and correlation development, a set of standard operating conditions has been established. These parameters are as follows:

- mill drive - $60 \mathrm{rpm}$

- race loading - $120 \mathrm{lbs}$ force

- sonic sifter classifier sieve - 100 mesh (U.S.)

- feed rate - approximately $20 \mathrm{~g} / \mathrm{min}$

- feed material - $16 \times 30$ mesh

The expression presently used in the correlations considers the mill drive (rpm) and the following variables:

- product rate $(\mathrm{g} / \mathrm{min})$

- fineness of product (\% -200 mesh)

- mill drive torque (in-lbs)

The intent is to characterize the grindability of a solid fuel as proposed for use. The test generates an index, Continuous Grindability Index (CGI), having the same units and application as the Hardgrove Grindability Index (HGI) determined by the ASTM Standard D-409. The inability of the Hardgrove method to adequately predict the full scale grindability characteristics of low rank coals of the United States prompted the development of a predictive method for these fuels. This resulted in a continuous grindability mill and index based on data points for a number of specific low rank western coals. Therefore, care should be exercised when unusual fuels or materials, such as corm and coal/ corn blends are being evaluated.

\section{RESULTS}

Dictated by the limitations discussed above, all five samples, coal, corn, and coal/corn blends were tested using the continuous mill. Summarized below are the reults of these tests.
Corn, M-40300 - Some difficulties were encountered while performing the test runs for this sample. Feed flow had to be constantly proded to maintain flow. The recycle continually increased due to sieve blinding. Since the continuous mill uses mechanical sieving in the classification system (Allen Bradley sonic sifter), the effect of air classification on this low density material could not be evaluated. Samples were collected from the outlet of the mill before it entered the classifier and particle size distributions were performed. The results of these sizing procedures were supportative of the fact that very little -100 mesh particles were being produced. Therefore it was not only the sieve blinding but also the low percentage of -100 mesh material that resulted in low product rates.

The build up of material and general behavior in the mill was not unlike many other materials such as low rank coal, except that the corn's adherence to the upper race and grinding balls was greater than normal but didn't cxcecd a thickness of more than one sixteenth of an inch.

Coal, C-14461 - Behavior of this coal during grinding in the continuous mill was comparable to that expected for a bituminous coal. No unusual problems were encountered. 


\section{DISCLAIMER}

This report was prepared as an account of work sponsored by an agency of the United States Government. Neither the United States Government nor any agency Thereof, nor any of their employees, makes any warranty, express or implied, or assumes any legal liability or responsibility for the accuracy, completeness, or usefulness of any information, apparatus, product, or process disclosed, or represents that its use would not infringe privately owned rights. Reference herein to any specific commercial product, process, or service by trade name, trademark, manufacturer, or otherwise does not necessarily constitute or imply its endorsement, recommendation, or favoring by the United States Government or any agency thereof. The views and opinions of authors expressed herein do not necessarily state or reflect those of the United States Government or any agency thereof. 


\section{DISCLAIMER}

Portions of this document may be illegible in electronic image products. Images are produced from the best available original document. 
Available from:

National Technical Information Service (NTIS)

U.S. Department of Commerce

5285 Port Royal Road

Springfield, Virginia 22161

Price: Printed copy: $\$ 4.50$

Microfiche: $\$ 3.00$ 
Prepared for U.S. Department of Energy

Assistant Secretary for Energy Technology

Division of Fossil Fuel Utilization

Washington, D.C. 20545
HCP/T3052-01

UC-93

\section{Corn/Coal Fuel \\ Characterization Study}

By P.L. Cioffi

Prepared by

Babcock \& Wilcox Co.

Barbarton, Ohio 44203

Under Contract No. ET-78-C-01-3052

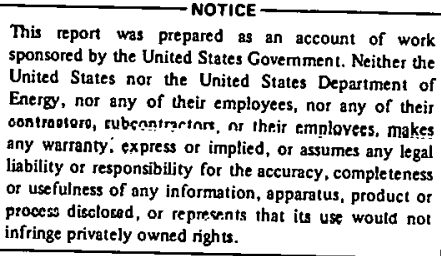

process disclosed, or represents that its use would not

I

$-\ldots$ 


\section{NOTICE}

This report was prepared as an account of work sponsored by the United States Government. Neither the United States nor the United States Department of Energy, nor any of their employees, makes any warranty, express or implied, or assumes any legal liability or responsibility for the accuracy, completeness, or usefulness of any information, apparatus, product, or process disclosed, or represents that its use would not infringe privately owned rights. Reference herein to any specific commercial product, process, or service by trade name. mark, manu facturer, or otherwise, does not necessarily constitute or imply its endorsement, recommondation, ur favoring by the United States Government or any agency thereof. The viaws and opinions of au thors expressed herein do not necessarily state or reflect those of the United States Gnvernmont or any ayency thereof, 


\section{INTRODUCTION}

At the request of the Department of Energy, laboratory analysis and tests were conducted to determine the suitability of shelled corn as a potential supplemental fuel for pulverized coal fired utility boilers.

The study consisted of standard analysis and test procedures which are routinely used for the characterization of coal and other solid fuels. A listing of the tests conducted is shown in Table No. 1.

It was assumed that, for utility boiler firing, the corm would be blended with coal at a pre-determined ratio prior to firing. Therefore, in addition to the base analysis of the corn and coal samples, blends of $10 \%, 20 \%$ and $30 \%$ corn prepared on a BTU basis were also tested. Both the corn and coal samples were provided by Public Service Company of Indiana. Sample identification and preparation data is provided in Appendix No. 1.

\section{RESULTS}

Table No. 2 shows the proximate and ultimate analysis data, BTU content, mositure, ASTM grindability and ash fusion temperature results for the base corn and coal samples. Table No. 3 shows the results of these tests for the three blend samples. Table No. 4 shows the ash analysis results for all of the samples tested. Appendicies No. 2 through No. 4 show the results of the burning profile, continuous grindability and corn ash melting point tests. Calculated slag viscosities are shown in Appendix No. 5.

\section{DISCUSSION AND CONCLUSIONS}

1. The analysis data of the corn sample indicates very high volatility and very low ash. The moisture content is relatively low compared to other biomass materials such as wood bark and bagasse. However, the ultimate analysis and BTU content of the corn on a dry basis is quite similiar to both bagasse and hard wood bark.

The coal sample tested is a typical, high volatile, high sulfur Eastem bituminous.

2. As expected, corn by itself would not be a suitable fuel for conventional PC fired utility boilers. This is primarily due to the severe fouling and slagging potential of corn ash which is discussed in detail below.

The relatively low BTU content of the corn and its low grindability would also result in extensive pulverizer capacity problems in existing units designed for coal firing. Based on the BTU content of the test samples, approximatcly $1.5 \mathrm{lbs}$ of corn would be required to equal the heat input from one pound of coal. Fuel flow requirements would, therefore, have to increase by $50 \%$ in order to maintain equivalent heat, input if corn were used to totally replace the coal. Additional pulverizer capacity would also be required to compensate for the low corm grindability noted on Table No. 2 and Appendix No. 3. The resulting total pulverizer requirements would be far in excess of the capacity normally available in a coal fired installation.

In addition, the proximate analysis results from the corm indicate extremely high volatility which would result in a high potential for bunker, feeder and pulverizer fires.

While the problems in the above areas would also preclude firing corn with coal at high corn percentages, the results of the blend sample tests discussed below indicate that the problems inherent with the corn can be minimized by blending at relatively low corn percentages.

3. As previously noted, the blend samples were prepared on a BTU basis. Therefore, the $10 \%$ blend contained $86 \%$ by weight coal and $14 \%$ corn. Approximately 1.05 pounds of this $10 \%$ by BTU blend would be required to provide the heat input equivalent of one pound of coal. While the total fuel weight input to the unit would increase by approximately $5 \frac{1}{2} \%$, the ash quantity would be reduced by close to $7 \frac{1}{2} \%$ due to the low ash content in the corn. Each additional $10 \%$ increase in corn input would increase the total fuel flow by an additional $5 \frac{1}{2} \%$ while the ash quantity would decrease by an additional $7 \frac{1}{2} \%$.

The additional fuel input will place a direct additional load on fuel handling and preparation equipment while the decrease in ash quantity will reduce the loading on ash han. dling and particulate type flue gas clean-up equipment. 
4. In addition to the required increase in pulverizer throughput noted above, the decrease in grindability measured in the blend testing would also have a direct affect on pulverizer performance. Normally, a decrease in grindability either results in a decrease in product fineness at constant pulverizer capacity or a reduction in capacity if fineness is maintained. In $\mathrm{B} \& \mathrm{~W}$ ball type pulverizers, a $12 \frac{1}{2} \%$ reduction in maximum capacity is required for each 10 point reduction in grindability in order to maintain fineness. This decrease in pulverizer capacity must be taken into account along with the increased throughput requirements noted above to determine if sufficient pulverizer capacity is available to maintain normal product fineness. In most instances, pulverizer installations are initially sized with sufficient excess capacity to absorb the grindability decrease measured for the $10 \%$ blend. Pulverizer capability at higher corn percentages would have to be evaluated on a case specific basis to determine if a significant reduction in fineness or capacity would be sustained. In any case, pulverizer power requirements would increase in proportion to the additional fuel flow requirements and the decrease in grindability.

5. As noted on Table No. 3 , volatility of the blend samples increases as the corn percentage increases. Fuel volatility is a direct indication of burner ignitability, stability and turndown capability. Accordingly, performance in these areas would tend to improve with the blends as compared to the coal although the coal analysis does not indicate that any problems would be expected in these areas.

6. The results of the Burning Profile 'l'est (Appendix No. 2) indicate that the burning characteristics of the coal is typical of a high volatile bituminous coal. .

The characteristics of the corn resemble those of a lignite with the exception of its high initial burning rate which is consistent with the large volatile matter content. The burning profiles of the blend samples are typical of the composite type results obtained with blended fuels.

Based on these profiles, no combustion related problems would be anticipated in firing any of the samples tested in utility boiler furnaces using conventional pulverized coal burners.
7. The most significant potential problem area with the corn/coal blends appears to be the slagging and fouling potentials. Slagging and fouling are the two types of high temperature ash deposition that can occur on the gas side of heat transfer surfaces in coal fired boilers. Fouling is defined as ash deposition on convection surfaces which are not exposed to radiant heat at flue gas temperatures down to $1400^{\circ} \mathrm{F}$. Ash deposition on a furnace surface which is exposed to radiant heat, or elsewhere if the deposit is in a molten state, is defined as 3lagying.

Twn parameters are primarily used to assess the slagging and fouling potentials of coals. These are the ash analysis data and the ash fusion temperatures. Using these parameters, $\mathrm{B} \& \mathrm{~W}$ has developed slagging and fouling indices which are used to categorize coals into either medium; high or severe fouling and slagging ranges. Based on past experience with coals in the various categories, the indices are used in the design of new units to select heat release rates, furnace sizing and tube spacing and to set sootblowers quantity and locations.

For the purposes of this study, examination of the indices is useful in that it allows generalized comparisons to be made between the coal and the various blends. It should be recognized, however, that since the indices were developed primarily for coals, significant deviations from the normal range of ash analysis tends to reduce the reliability of the indices for predicting full scale performance. It should also be noted that the actual performance of any fuel in regards to slagging and fouling depends not only on the characteristics of the fuel but also on the boiler design crileria mentioned above. A high fouling and slagging coal may not cause. any problems in a conservatively designed unit, while a coal in the medium slagging and fouling ranges could cause severe problems in a unit with high furnace heat release rates and tight tube spacing.

Calculation of the slagging and fouling indices for the coal sample shows that the coal would fall into the medium slagging, high fouling categories. Due primarily to the high phosphorus concentration in the ash, the standard indices cannot be directly applied to the corn ash. However, the test results in Appendix No. 4 show extremely low ash fusion temperatures. The hot stage microscope was used in 
this test since the corn ash softening teinperature was too low for measurement by standard methods. The $1260^{\circ} \mathrm{F}$ softening temperature falls well below the fusion temperatures observed even in severe fouling and slagging indexed coals. Corn fired by itself would, therefore, undoubtably result in severe slagging and fouling problems which would preclude its use as a primary fuel in a utility boiler.

The ash analysis data from the blend samples indicates that the ash constituents differ only slightly from the coal ash analysis. The calculated ash viscosities of the blend samples (Appendix No. 5) also show no significant change from the coal ash viscosity. This is due to the relatively low percentage blends and the low ash content of the corn. Applying the same slagging and fouling indices used for the coal sample, all of the blends would fall into the same medium slagging, high fouling categories. In fact, some improvement is noted in the indices due to the reduction in sulfur in the. fuel and sodium in the ash.

These results may be somewhat misleading, however, due to the increasing percentages of phosphorus in the ash from the blends. The corn ash contains over $51 \%$ phosphorus which has a signficant impact on the blend ash. Normally, the percentage of phosphorus in the ash of most coals is negligable (approximately $.1 \%$ ) as is the case with the coal sample tested. For this reason, phosphorus content is not talken into account in the slagging and fouling indices. Experience with the rare high phosphorus coals has, however, indicated relatively severe fouling potentials when phorsphorus is in the $2-3 \%$ range. Therefore, the phosphorus content in the higher percentage blends may become a significant factor in this regard.

Examination of the fusion temperatures for the blend samples and their comparison to the coal ash fusion temperatures provides a more direct indication of slagging and fouling potentials. As shown on Tables 1 and 2, the ash initial deformation temperatures are depressed by approximately $100^{\circ} \mathrm{F}$ for each $10 \%$ increase in BTU input from corn. It follows that, if marginal slagging and fouling conditions exist with the coal, the addition of corn may cause significant problems in these areas. If, on the other hand, coal ash fusion temperatures are relatively high, the reduction in fusion temperature resulting from the addition of corn will probably not result in problems as long as fusion temperature depression versus corn percentage is similiar to that measured. with the corn and coal samples tested.

Since the actual full scale performance of the blends in regards to fouling and slagging is dependent upon the characteristics of the coal being fired and the design of the steam generator or boiler, judgements regarding the potential for problems in these areas must be made on a case specific basis. In the case of the coal sample tested, it is our opinion that corn blends in the 10 to $15 \%$ range could be accommodated in most modern PC fired utility boilers with minimal risk. The more conservatively designed units firing coals with lower slagging and fouling potentials could potentially utilize mixtures containing up to $25 \%$ corn on a BTU basis. 
Table No. 1

TESTS AND ANALYSIS PERFORMED

ASTM PROCEDURES

Total Moisture

Ultimate Analysis

Proximate Analysis

BTU Content

Grindability

Ash Fusion Temperatures

\section{B\&W PROCEDURES}

Spectrographic Ash Analysis

Burning Profile

Continuous Grindability Calculated Slag Viscosity

Table No. 2

Sample No.

C-14461.

$M-30400$

Sample Description

Coal Sample

Corn Sample

Total Moisture, \%

17.6

17.3

Proximate Analysis (Dry), \%

Volatile Matter

40.3

45.7

14.0

87.6

11.2

Ash

67

27

12230

8130

14220

8230

BTU per lb. (M\&A Free)

Ultimate Analysis (Dry), \%

Carbon

68.1

46.5

Hydrogen

4.9

1.2

6.5

Nitrogen

Sulfur

Ash

Oxygen (Diff.)

Total

3.1

1.6

14.0

0.1

$\frac{8.7}{100.0}$

44.1

100.0

Ash Fusion Temperatures, ${ }^{\circ} \mathrm{F}$

Atmosphere

A (I.D.)

B (S.T., Sp)

C (S.T., HSp)

D (F.T., 1/16")

E (F.T., Flat)
Red.

2100

2420

2460

2580

2650
Dxid.

2350

2500

2540

2670

$2750+$ 
Table No. 3

Sample No.

Sample Description

F-1426
Corn \& Coal
Blend
$10 \%$ Corn
$90 \%$ Coal
on a BTU Basis

Proximate Analysis (Dry), \%

Volatile Matter

Fixed Carbon

Ash

Grindability (ASTM D-409)

BTU per lb. (Dry)

BTU per lb. (M\&A Free)

Ultimate Analysis (Dry), \%

\begin{tabular}{lr} 
Carbon & 65.0 \\
Hydrogen & 5.2 \\
Nitrogen & 1.3 \\
Sulfur & 2.3 \\
Ash & 12.3 \\
Oxygen (Diff.) & 13.9 \\
\cline { 2 - 2 } Total & 100.0
\end{tabular}

46.9

40.8

12.3

57

11620

13250

\begin{tabular}{|c|c|}
\hline$F-1427$ & F-1428 \\
\hline $\begin{array}{l}\text { Corn \& Coal } \\
\text { Blend } \\
20 \% \text { Corn } \\
80 \% \text { Coal } \\
\text { on a BTU Basis }\end{array}$ & $\begin{array}{l}\text { Corn \& Coal } \\
\text { Blend } \\
30 \% \text { Corn } \\
70 \% \text { Coal } \\
\text { on a BTU Basis }\end{array}$ \\
\hline
\end{tabular}

52.8

36.5

10.7

58.9

31.8

9.3

49

42

11050

12370

10610

11700

62.2

5.3

1.4

2.1

10.7

59.9

5.5

1.5

1.7

9.3

22.1

100.0

Ash Fusion Temperatures, ${ }^{\circ} \mathrm{F}$

\begin{tabular}{|c|c|c|c|c|c|c|}
\hline Atmosphere & Red. & Oxid. & Red. & Oxid. & Red. & Oxid. \\
\hline $\begin{array}{ll}\text { A } & \text { (I.D.) } \\
\text { B } & \text { (S.T., Sp) } \\
\text { C } & \text { (S.T., HSp) } \\
\text { D } & \text { (1-.I., 1/16") } \\
\text { E } & \text { (F.T., Flat) }\end{array}$ & $\begin{array}{l}2010 \\
2160 \\
2230 \\
2480 \\
2750+\end{array}$ & $\begin{array}{l}2260 \\
2460 \\
2500 \\
2840 \\
2750+\end{array}$ & $\begin{array}{l}1990 \\
2120 \\
2210 \\
2420 \\
2750+\end{array}$ & $\begin{array}{l}2180 \\
2400 \\
2460 \\
2640 \\
2750+\end{array}$ & $\begin{array}{l}1990 \\
2100 \\
2190 \\
2420 \\
2750\end{array}$ & $\begin{array}{l}2160 \\
2370 \\
2400 \\
2560 \\
2750+\end{array}$ \\
\hline
\end{tabular}


Table No. 4

ANALYSIS - COAL \& CORN ASH \& ASH FROM COAL/CORN BLENDS

Sample No.

Sample Description

\begin{tabular}{lll} 
C-14461 & M-30400 & F-1426 \\
\cline { 3 - 3 } Ash Prepared & $\begin{array}{c}\text { Ash Prepared Ash Prepared } \\
\text { From }\end{array}$ & From Whole \\
Coal Sample & Krom 10\% Corn- \\
Kernel Corn & $\begin{array}{l}90 \% \text { Coal on } \\
\text { BTU Basis }\end{array}$
\end{tabular}

BTU Basis
F-1427

Ash Prepared

From 20\% Corn-

$80 \%$ Coal on

BTU Basis
$F-1428$

Ash Prepared

From 30\% Corn$70 \%$ Coal on BTU Basls

Wet Chemical Analysis, \%

Silicon as $\mathrm{SIO}_{2}$

- Aluminum as $\mathrm{Al}_{2} \mathrm{O}_{3}$ Iron as $\mathrm{Fe}_{2} \mathrm{O}_{3}$ Titanium as $\mathrm{TiO}_{2}$ Calcium as $\mathrm{CaO}$ Magnesium as $\mathrm{MgO}$ Sodium as $\mathrm{Na}_{2} \mathrm{O}$ Potassium as $\mathrm{K}_{2} \mathrm{O}$ Sulfur as $\mathrm{SO}_{3}$

Phosphorus as $\mathrm{P}_{2} \mathrm{O}_{5}$ Carbon as $\mathrm{C}$
48.2

21.3

15.3

0.8

3.5

0.6

0.9

2.5

3.8

0.1
0.9

$<0.1$

0.4

$<0.1$

0.6

13.8

0.3

30.1

0.5

51.9

0.5
47.8

20.3

15.1

0.8

3.4

1.1

0.5

2.7

4.5

1.1
47.2

19.9

14.9

0.6

3.2

1.4

0.5

3.1

4.7

2.2
46.4

19.8

14.7

0.6

3.2

1.5

0.5

3.6

4.9

3.2 
Appendix No. 1

Sample Identification 


\section{SAMPLE IDENTIFICATION}

The samples provided for testing and analysis at ARC were:

Whole corn kernel

Unidentified bituminous coal

The corn and coal were blended on a BTU basis at ARC as listed and identified below:

Chem Lab

Sample No.

M-30400

C-14461

Unidentified Bituminous Coal

F-1426

F 1127

F-1428
Blend of $10 \%$ Corn (M-20400) and $90 \%$ Coal (C-14461) prepared on a BTU basis

Blend of 20\% Corn (M 30100) and $80 \%$ Coal (C-11161) prepared on a BTU basis

Blend of $30 \%$ Corn (M-30400) and 70\% Coal (C-11161) prepared on a BTU basis
Preparation*

Air drled and (1) reduced to -60 mesh for fuels analysis and Burning Profile, (2) reduced to $16 \times 30$ mesh for grindability tests

Air dried and (1) reduced to -60 mesh for fuels analysis and Burning Profile, (2) reduced to $16 \times 30$ mesh for grindability tests

Required amounts of each component were combined and intimately mixed by rolling.

R.cquircd amounts of cach component werc combined and intimately mixed by rolling.

Required amounts of each componcint wcre combined and intimately mixed by rolling.

* Air drying and size reduction were performed using standard ASTM procedures described in the 1977 Annual Book of ASTM Standards. 
Appendix No. 2

Burning Profile Test 


\section{APPARATUS}

The burning profile tests were performed on each sample using an apparatus as described in Appendix A. The samples were prepared to -60 mesh and tested in conformance with the procedures described by C. L. Wagoner and A. F. Duzy in "Burning Profiles for Solid Fuels”, ASME 67-WA/FU-4.

\section{RESULTS}

Figure 1 through 5 display the burning profiles of the five samples under investigation. The comparison of burning profiles for coals of different rank (Figure 6) is presented for reference of typical behavior of rate of weight loss versus increasing temperature. 


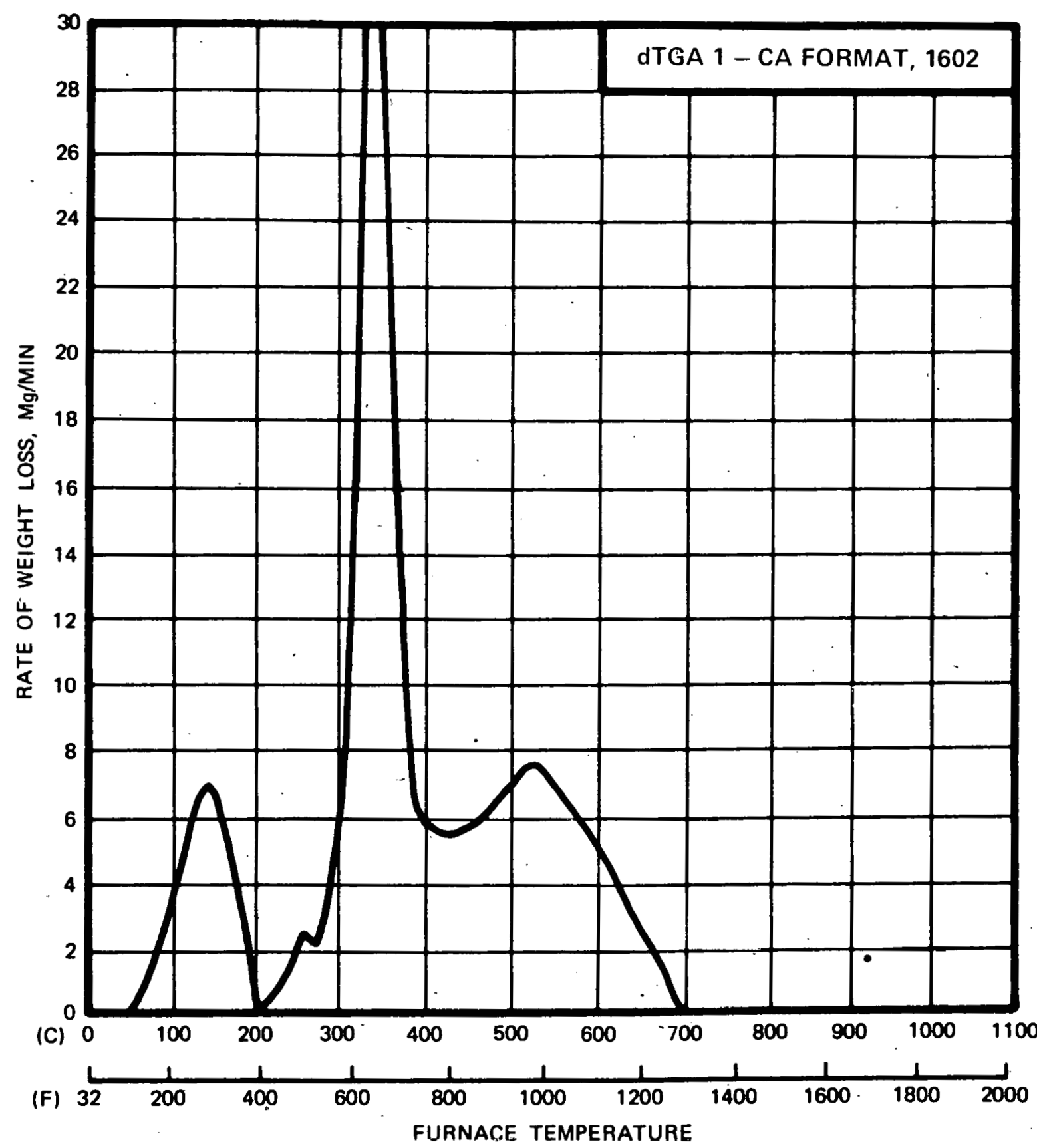

(C)

FIGURE 1 BURNING PROFILE FOR SAMPLE M-30400, WHOLE KERNEL CORN 


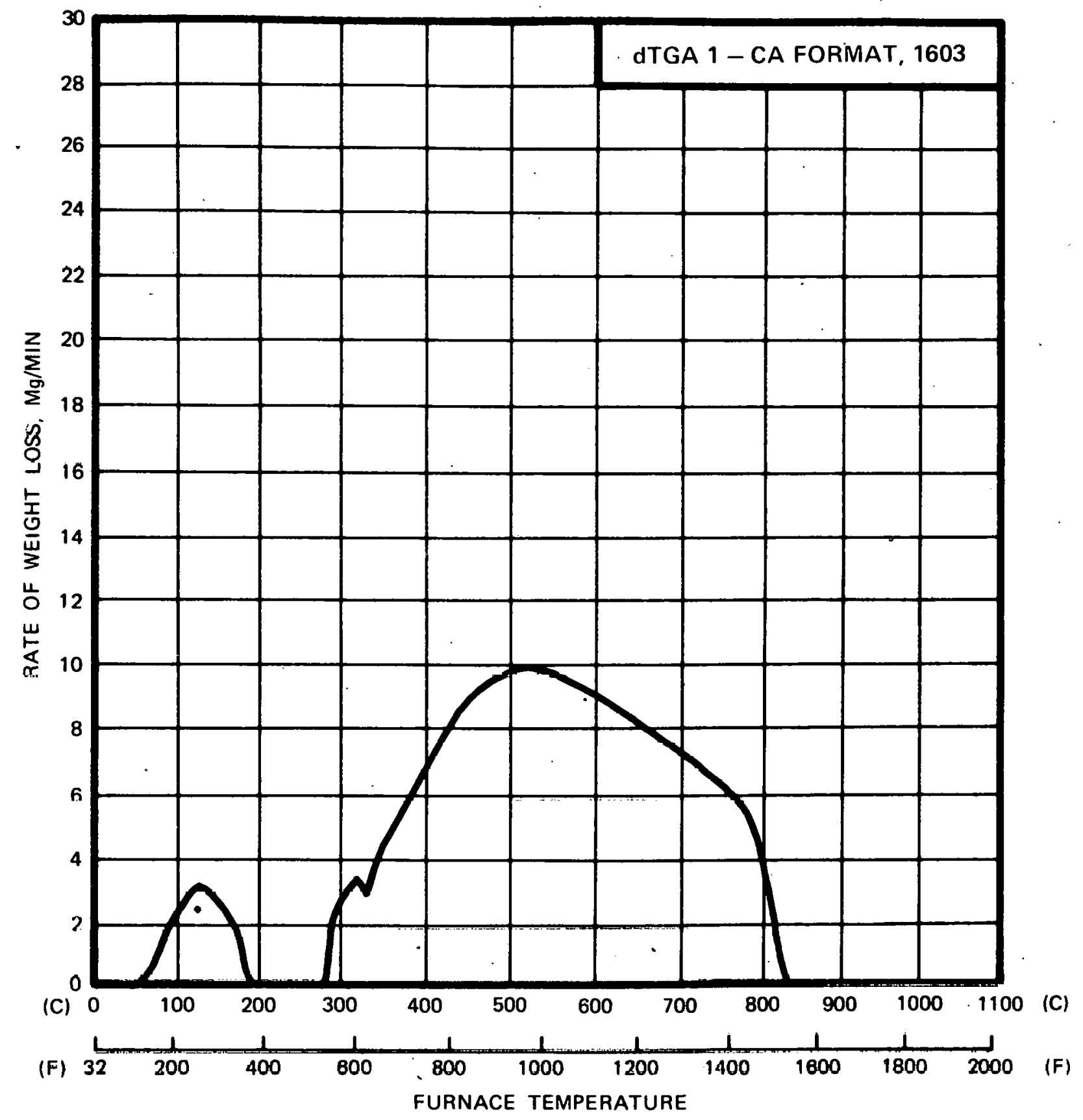

FIGURE 2 BURNING PROFILE FOR SAMPLE C-14461, UNIDENTIFIED BITUMINOUS COAL 


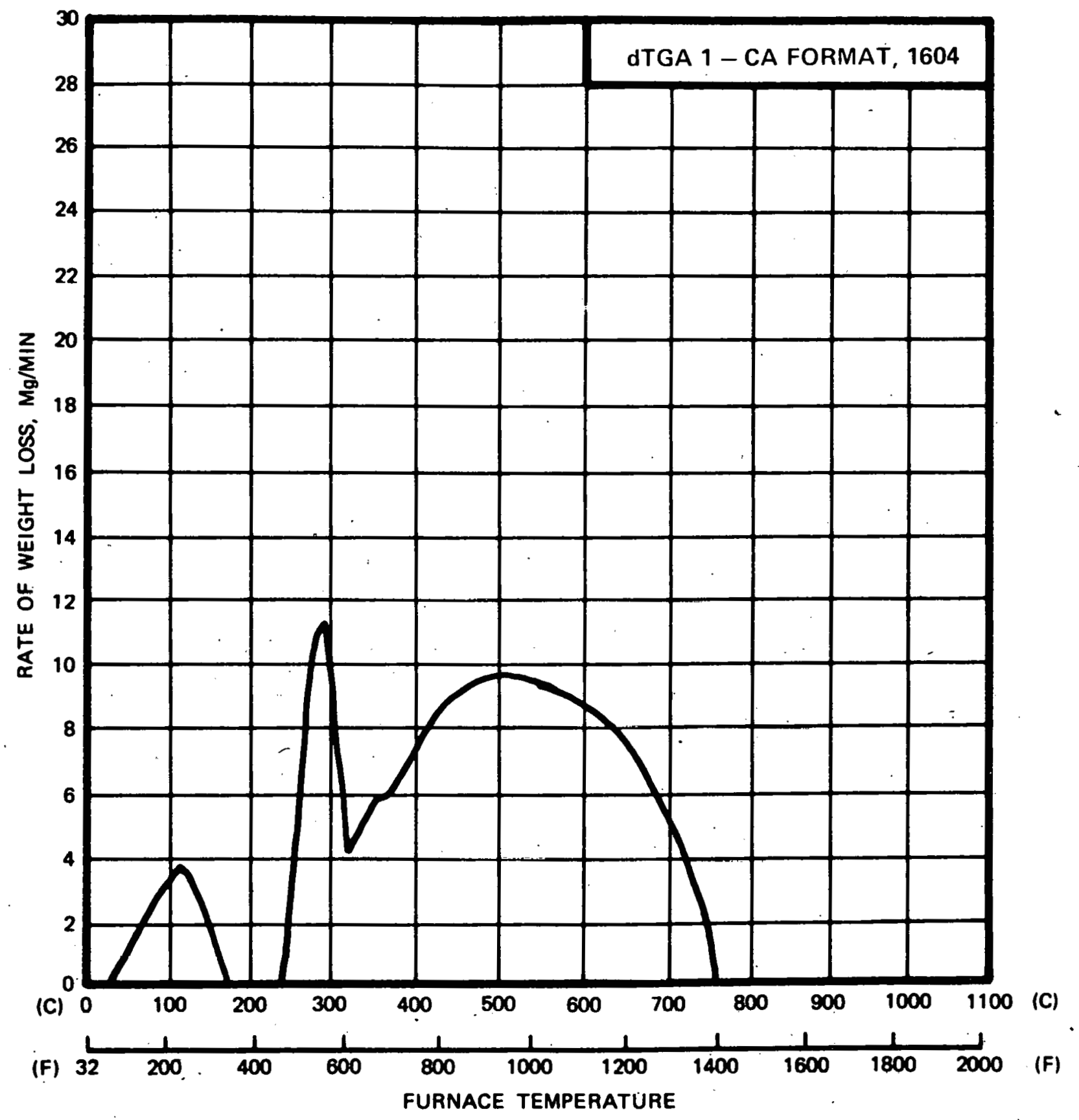

FIGURE 3 BURNING PROFILE FOR SAMPLE F-1426, BLEND OF 10\% CORN $90 \%$ COAL PREPARED ON A BTU BASIS 


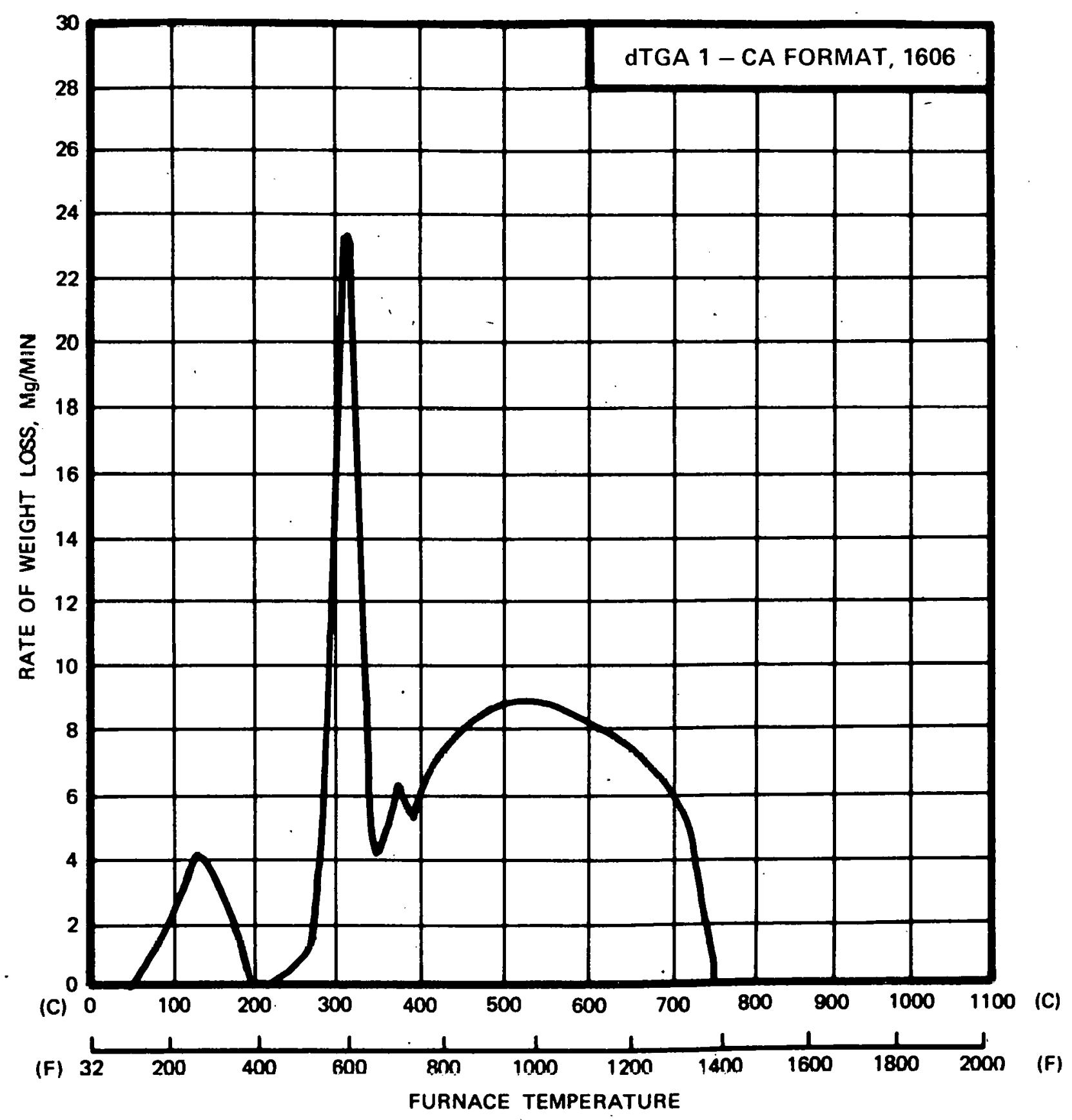

FIGURE 4 - BURNING PROFILE FOR SAMPLE F-1427, BLEND OF $20 \%$ CORN $80 \%$ COAL PREPARED ON A BTU BASIS 


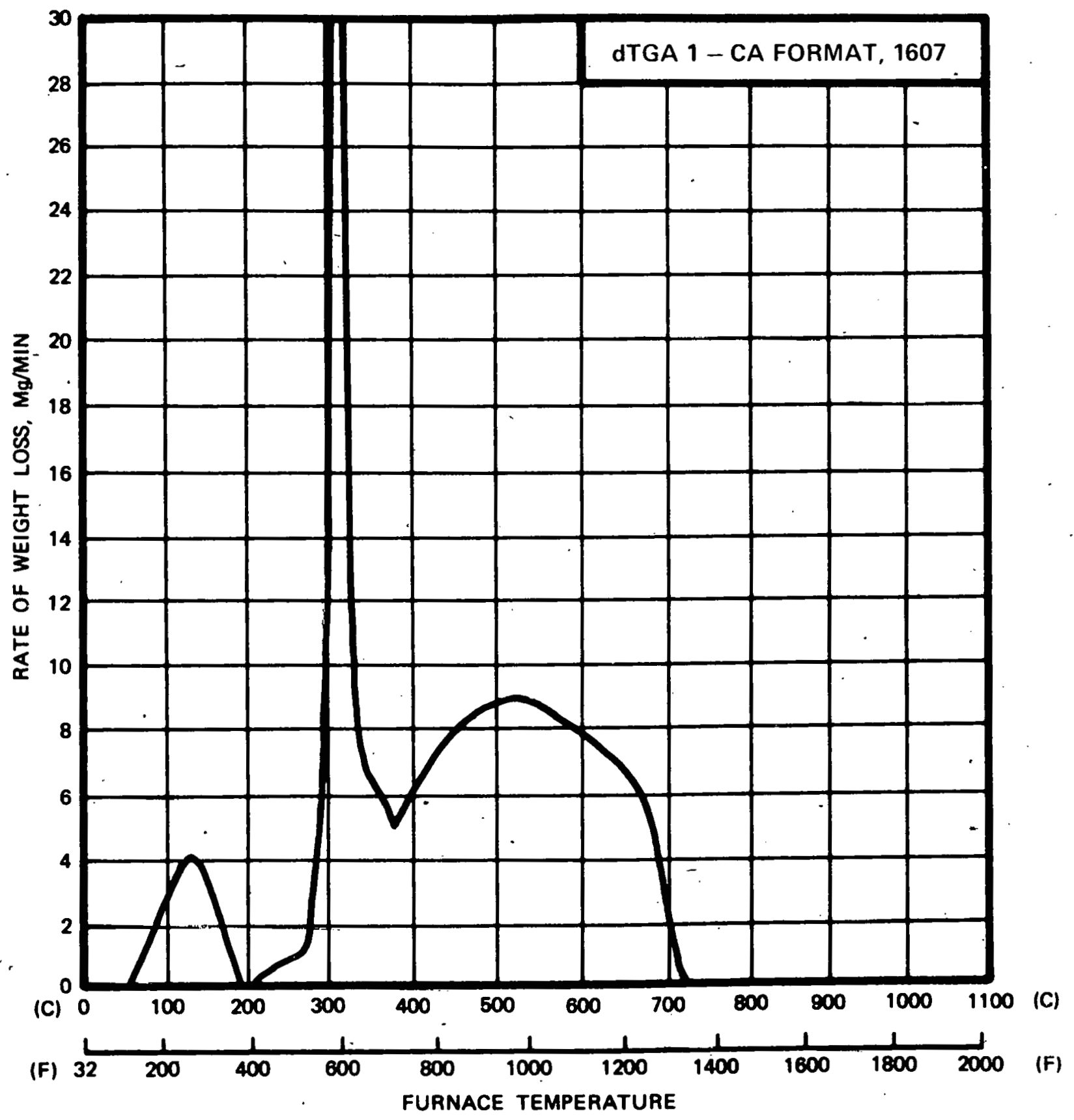

FIGURE 5 BURNING PROFILE FOR SAMPLE F-1428, BLEND OF $30 \%$ CORN 70\% COAL PREPARED ON A BTU BASIS 

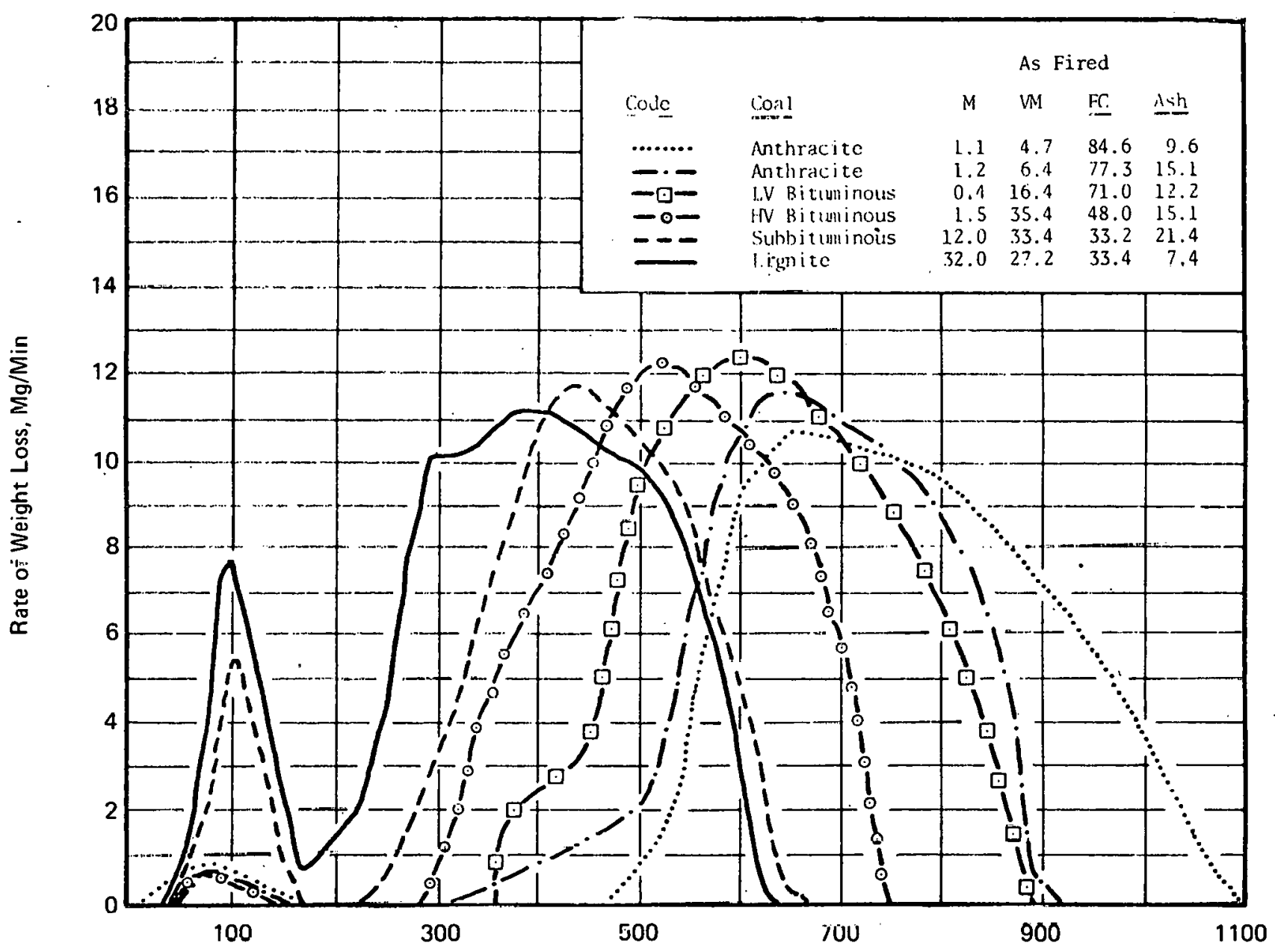

Furnace Temperature, ${ }^{\circ} \mathrm{C}$ 
Appendix No. 3

Continuous Grindability Tests 
Blends, F-1426, F-1427 and F-1428 - The blends' behavior was more like that of the coal. Some minor difficulties were experienced with F-1428. Feed flow for F-1428 was erratic and product rates between test runs were not as consistent as the other blends. 
Appendix No. 4

Melting Point of Corn Ash 


\section{APPARATUS}

The melting point of the corn ash was determined using a Leitz hot stage microscope. The instrument was calibrated by measuring the melting point of Gold and Zinc metals.

\section{RESULTS}

The corn ash softening was observed to be approximately $1260^{\circ} \mathrm{F}$ and the melting temperature to be approximately $1330^{\circ} \mathrm{F}$. 
Appendix No. 5

Calculated Slag Viscosity 


\section{BACKGROUND}

In 1976 a computer correlation relating slag viscosity to ash composition of coal was developed at $B \& W$. The publication, "Empirical Correlation of Coal Ash Viscosity with Ash Chemical Composition", by S. M. Barrick and G. F. Moore, ASME 76-WA/FU-3, describes the procedure and types of fuels used in the correlation. It is appropriate to emphasize that the correlation is based on primarily United States coals, basically bituminous with some sub-bituminous and lignite types included. Therefore if the ash composition of the material to be evaluated is outside the range of those used in the correlation, the results obtained should be used cautiously.

\section{RESULTS}

Presented below are Tables 1 through 4, viscosity and temperature values that were obtained from best-fit curves based on the output data from the empirical correlation. The calculated values for the reducing atmospheres appeared to be good fits . for all the samples. When the oxidizing atmosphere was considered it was found that a greater amount of value judgement had to be employed to obtain curves useful for evaluations. This was true for the coal sample under consideration as well as the blends.

Viscosity values for the corn (M-40300) were not obtainable through the empirical relationship previously discussed. This is probably due to the vast difference in composition of the corn ash compared to the bituminous coal ash. The addition of the corn to the coal, in the percentages requested, apparently had little effect on the outputs from the correlation. 
TABLE 1

COAL ASH VISCOSITY AND TEMPERATURE

Sample C14461

$100 \%$ Coal

\begin{tabular}{|c|c|c|}
\hline $\begin{array}{l}\text { Viscosity } \\
\text { Poise } \\
\end{array}$ & $\begin{array}{l}\text { Calculated } \\
\text { Oxidizing } \\
\end{array}$ & $\begin{array}{c}\text { Temperature }{ }^{\circ} \mathrm{F} \\
\text { Reducing }\end{array}$ \\
\hline $\begin{array}{r}50 \\
100 \\
250 \\
500 \\
1000 \\
3000 \\
5000 \\
10000\end{array}$ & $\begin{array}{l}2955 \\
2785 \\
2635 \\
2555 \\
2485 \\
2390 \\
2367 \\
2330\end{array}$ & $\begin{array}{l}2955 \\
2750 \\
2594 \\
2506 \\
2437 \\
2352 \\
2316 \\
2275\end{array}$ \\
\hline
\end{tabular}

TABLE 3

80/20 BLEND ASH VISCOSITY AND TEMPERATURE

Sample F 1427

$80 \%$ Coal, $20 \%$ Corn-Blend Btu Basis

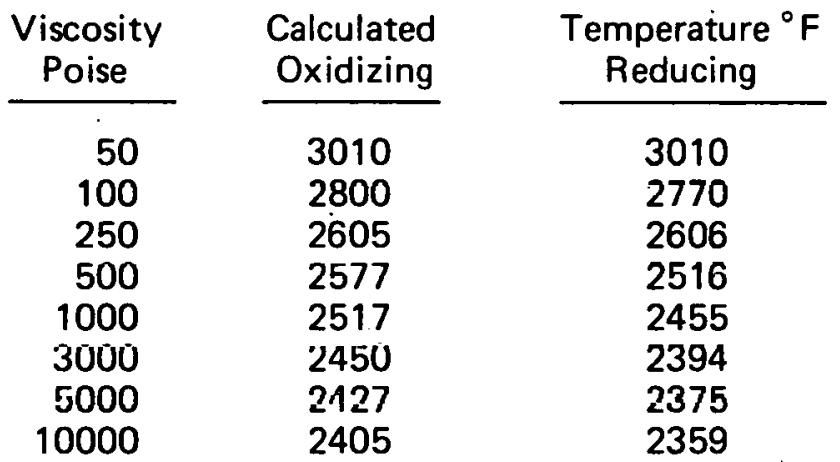

TABLE 2

90/10 BLEND ASH VISCOSITY AND TEMPERATURE

Sample F 1426

90\% Coal, 10\% Corn-Blend Btu Basis

\begin{tabular}{|c|c|c|}
\hline $\begin{array}{c}\text { Viscosity } \\
\text { Poise }\end{array}$ & $\begin{array}{l}\text { Calculated } \\
\text { Oxidizing } \\
\end{array}$ & $\begin{array}{c}\text { Temperature }{ }^{\circ} \mathrm{F} \\
\text { Reducing }\end{array}$ \\
\hline 50 & 2962 & 2962 \\
\hline 100 & 2775 & 2770 \\
\hline 250 & 2649 & 2615 \\
\hline 500 & 2580 & 2526 \\
\hline 1000 & 2526 & 2455 \\
\hline 3000 & 2490 & 2356 \\
\hline 5000 & 2440 & 2313 \\
\hline 10000 & 2412 & 2285 \\
\hline
\end{tabular}

TABLE 4

70/30 BLEND ASH VISCOSITY AND TEMPFRATURE

Sample F 1428

70\% Coal, 30\% Corn-Blend Btu Basis

\begin{tabular}{|c|c|c|}
\hline $\begin{array}{l}\text { Viscosity } \\
\text { Poise }\end{array}$ & $\begin{array}{c}\text { Calculated } \\
\text { Oxidizing }\end{array}$ & $\begin{array}{c}\text { Temperature }^{\circ} \mathrm{F} \\
\text { Reducing }\end{array}$ \\
\hline 50 & 3015 & 3015 \\
\hline 100 & 2780 & 2765 \\
\hline 250 & 2647 & 2595 \\
\hline 500 & 2580 & 2500 \\
\hline 1000 & 2527 & 2435 \\
\hline 3000 & 2470 & 2366 \\
\hline 5000 & 2452 & 2345 \\
\hline 10000 & 2430 & 2324 \\
\hline
\end{tabular}


Attachment A

\section{Arc Burning Profile System}




\section{ARC BURNING PROFILE SYSTEM}

A schematic diagram of the standard apparatus used for this test is shown in Figure A-1. This system permits derivative thermogravimetric analysis (dTGA) of oxidation of a fuel under controlled conditions. To accomplish this, continuous and simultaneous measurements of the rate of weight change and temperature of the heated sample are made. The essential components of this system are as follows: a furnace and temperature programmer/ controller to heat the sample fuel at a fixed rate, an electronic balance and time derivative computer to continuously measure the weight of the sample and determine its rate of weight change, and finally an $X-Y$ recurder to simultaneously record the furnace temperature in close proximity to the sample and the rate of weight change from the lime derivative computer.

The sample is contained in a platinum crucible 1 inch in diameter and $1 / 2$ inch deep suspended in a quartz tube surrounded by the furnace. A metered air flow is introduced into the bottom of the quartz tube.

The Burning Profile, a plot of rate of sample weight loss as the temperature increases, is used to evaluate the combustion of both solid and liquid fuels. In the case of solid fuels $300 \mathrm{mg}$ of -60 mesh material, prepared in accordance with ASTM D271-64, is spread in a uniform thin layer across the bottom of the sample crucible. For liquids, 300 $\mathrm{mg}$ of as-received material is used. In the standard test, solid fuel samples are heated at a rate of $27^{\circ} \mathrm{F} / \mathrm{min}$ (solid fuel mode) and liquid fuels at $5.4^{\circ} \mathrm{F} / \mathrm{min}$ (liquid fuel mode).

The technical paper, "Buming Profiles for Solid Fuels" by C. L. Wagoner and A. F. Duzy provides additional details perlaining to the construction of the Burning Profile System and its application to the evaluation of coal and char combustion. 


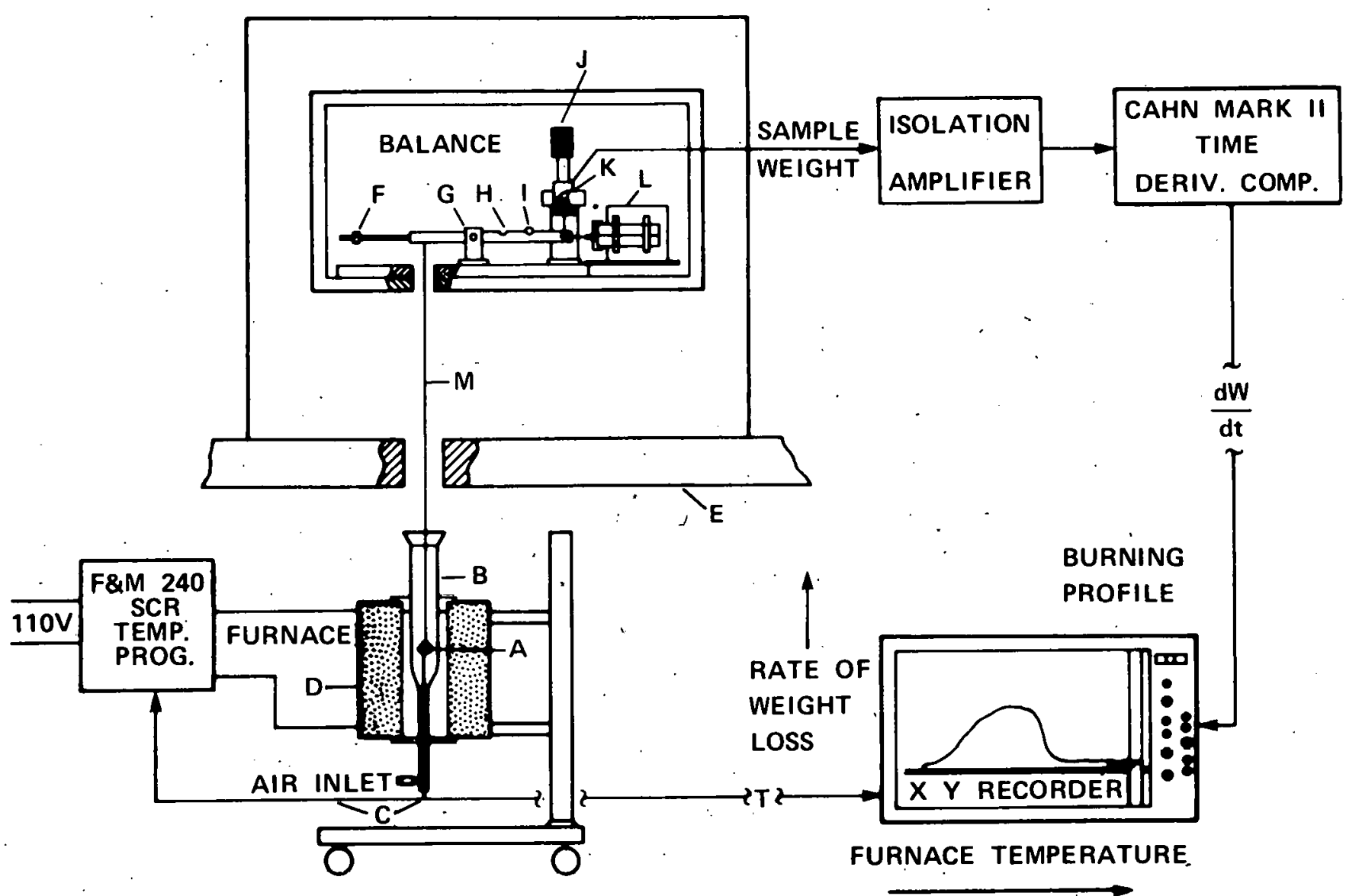
A - PLATINUM SAMPLe CRUCIBLE
H - BALANCE BEAM
B - VYCOR TUBE
I - RIDER WEIGHT
C - THERMOCOUPLES
$J$ - MICROMETER NULL ADJUSTMENT
D - SPLIT CHEST FURNACE
E - TABLE TOP
F - TARE WEIGHT
K - D C D T DISPLACEMENT TRANSDUCER
G - BENDIX FREE-FLEX PIVOT
L - MAGNETIC DAMPER
M - NICHROME SUSPENSION 0.004 INCH DIAMETER

FIGURE 1 SCHEMATIC OF DERIVATIVE THERMOGRAVIMETRIC ANALYSIS SYSTEM 
Attachment B

Arc Laboratory-Scale Continuous Mill for Grindability Studies 


\section{LABORATORY-SCALE CONTINUOUS MILL . FOR GRINDABILITY STUDIES}

The Laboratory-Scale Continuous Mill is used for evaluating the pulverization characteristics of coal and other solid materials. This mill, shown in Figure A-1, incorporates many of the features of $B \& W E, E L$, and CR pulverizers. The $16 \times 30$ mesh coal is fed through a pipe into the grinding zone by a Vibra-Screw Feeder. For coal, feed flow rates are generally maintained at about 20 grams per minute. The upper race of the mill is connected through a drive shaft and a gear box to a variable speed motor. Loading of the grinding balls is accomplished by suspending weights on the outer arm of a lever connected to the base of the mill.

The general construction of the grinding zone shown in Figure A-2 is similar in dimension to the Hardgrove Mill. It consists of a steel container with a race mounted on the inside bottom. Nine 1.5-inch stainless steel ball bearings sit on the lower race and are driven by the upper race. The upper race is open on top permitting coarse coal to enter the grinding chamber where it falls upon the conical center of the lower race. To ensure that all the coal falling into the mill is directed to the grinding area, a knife edge connected to the moving upper race forces coal remaining on the central cone onto the lower race. The coal particles move into the grinding area, are ground, and are subsequently displaced to a space on the outside edge of the lower race by more incoming coal.

The pulverized coal swept from the grinding zone is gravity fed through a 1.5-inch pipe into an Allen Bradley Sonic Sifter. Sieves of different mesh may be used in the sifter. Sonic energy is used to accomplish the sieving with a minimum of additional grinding. The pulverized product coal and the coarser coal requiring recycling are each directed to separate compartments at the bottom of the sonic sifter. The product is continuously collected and weighed in a tared polyethylene tray. The coarse coal is accumulated for periodic introduction into the recycle system.

The position of the torque sensor has been changed from that shown in Figure A-1. The torque on the mill drive shaft is presently measured by a Lebow reaction-type torque sensor positioned below the mill bowl as shown in Figure A-3. A thrust bearing rated at 2,000 pounds in the bowl support carries the vertical loading and excludes this force component from the measured torque. 


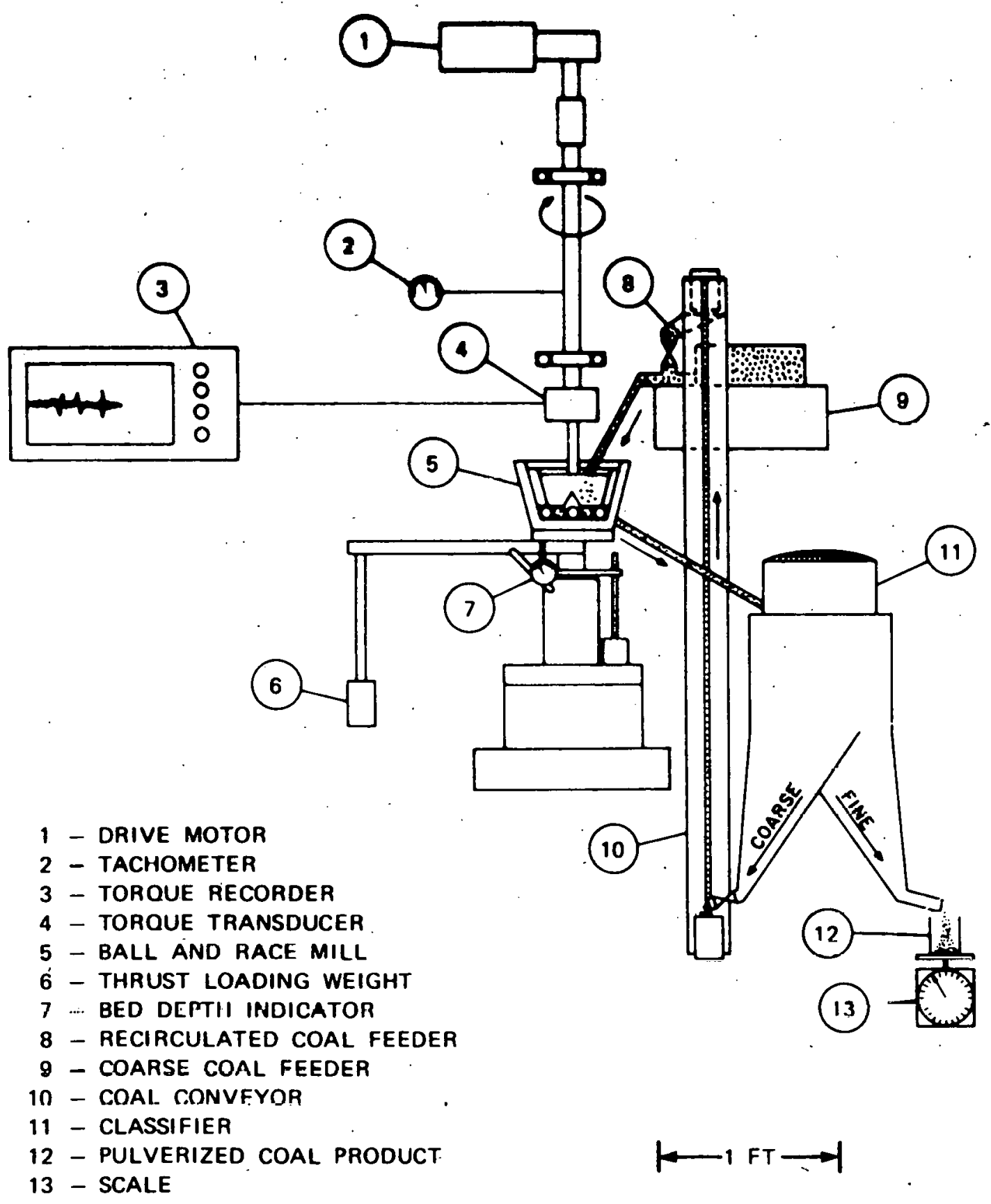

FIGURE 1 SCHEMATIC OF LABORATORY-SCALE CONTINUOUS MILL 

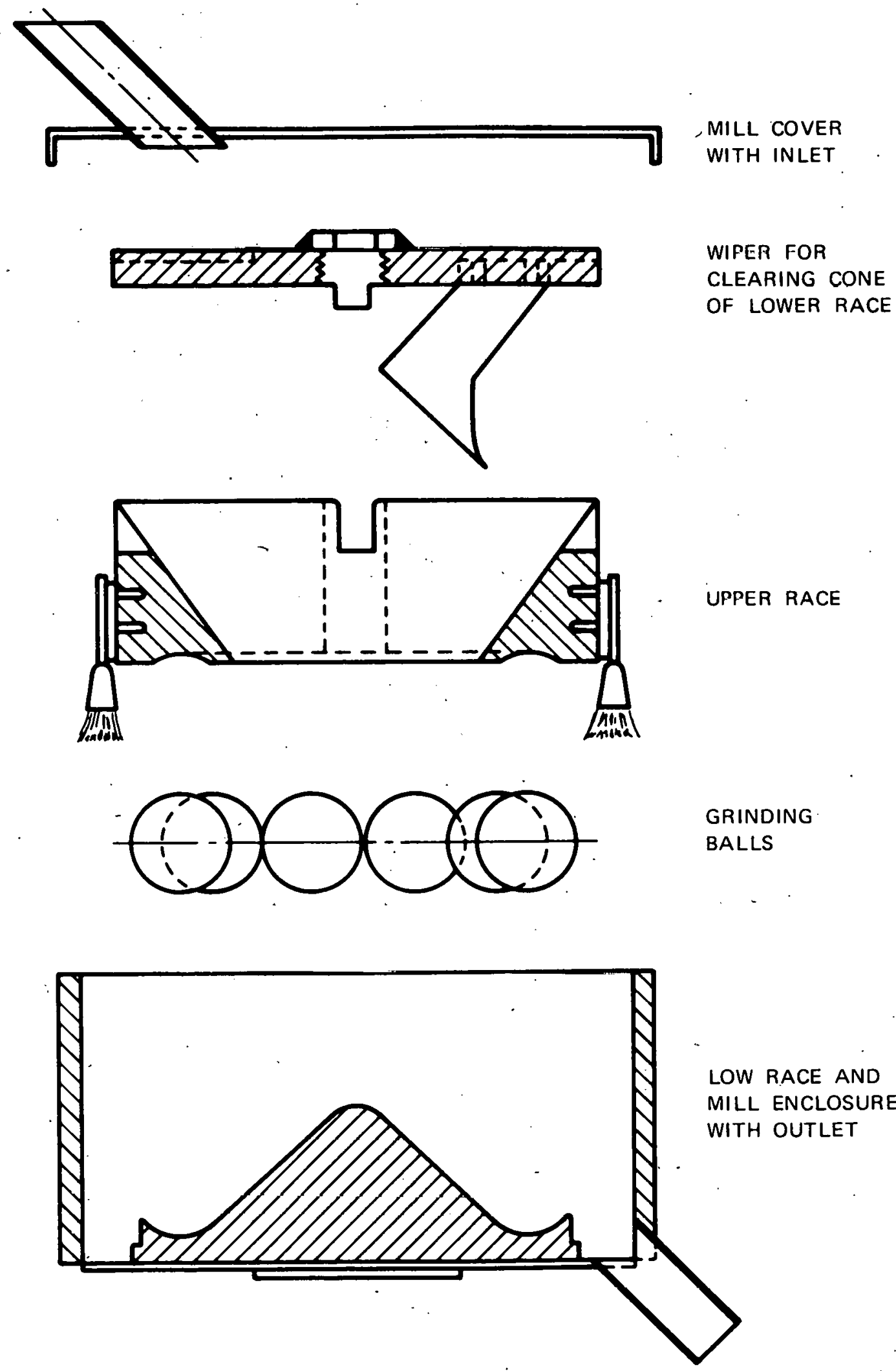

FIGURE 2 EXPLODED VIEW OF THE LABORATORY-SCALE CONTINUOUS MILL GRINDING ZONE 


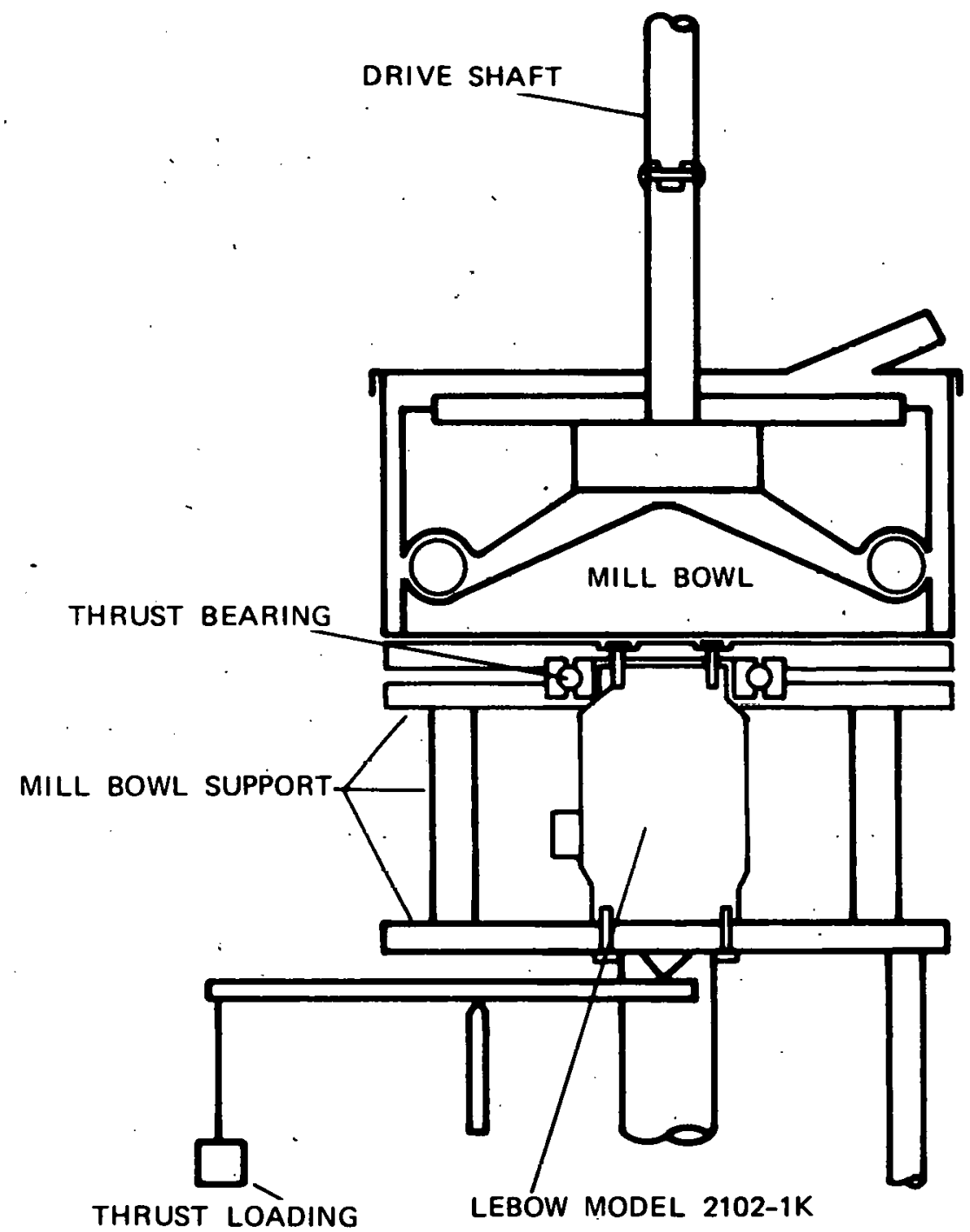

FIGURE 3 TOROUE SENSOR AND MILL.BOWL SUPPORT DESIGN 